\title{
Influence of adding of laurel essential oil extracts on salad dressings properties
}

\section{Kremena Nikovska ${ }^{1}$, Galina Stefanova ${ }^{1}$, Lyubomir Stefanov ${ }^{2}$, Stanka Damyanova ${ }^{3}$, Albena Stoyanovaa ${ }^{1}$, Oleksii Gubenia ${ }^{4}$}

\author{
1 - University of Food Technologies, Plovdiv, Bulgaria \\ 2 - Lotos Expert Ltd, Plovdiv, Bulgaria \\ 3 - University of Ruse, Branch - Razgrad, Bulgaria \\ 4 - National University of Food Technologies, Kyiv, Ukraine
}

Keywords:

Laurel

Leaves

Extracts

Chemical

Composition

Salad

\section{Article history:}

Received

20.06.2017

Received in revised

form 22.08.2017

Accepted 05.09.2017

\section{Corresponding}

author:

Stanka Damyanova

E-mail:

sdamianova@uni-

ruse.bg

DOI:

10.24263/2304-

974X-2017-6-3-4
Abstract

Introduction. The objective of this study was to characterize essential oil extracts from laurel (Laurus nobilis L.) leaves and to develop sensory profiles of salad dressings with these extracts.

Materials and methods. Laurel leaves (Laurus nobilis L.) originating from the Athon peninsula, northern Greece were used and they were picked in October 2016. The salad dressings, which are belonged to oil-in-water emulsions, were produced with the addition of essential oil extracts from dried and humid laurel leaves.

Results and discussion. There were identified 46 components in the extracts which are represented approximately $97 \%$ of the total content. The main components in dry leaves extract are: 1,8-cineole $(43.65 \%), \alpha$-terpinyl acetate $(15.10 \%)$, calarene $(8.48 \%), \beta$ bisabolene $(3.89 \%)$ and $p$-cymene $(3.12 \%)$; in humid leaves extract 1,8 -cineole $(45.94 \%), \alpha$-terpenyl acetate $(15.89 \%)$, calarene $(8.92 \%)$, $\beta$-bisabolene (5.09\%), $p$-cymene (3.28\%) and terpinen-4-ol (3.03\%).

The two extracts had difference by content of aromatic components from those obtained with ethanol. There were differences in the composition of the essential oils, and this was probably due to the method of production.

In the extract obtained from dry leaves dominated monoterpene oxygen-containing derivatives $(68.47 \%)$, sesquiterpene hydrocarbons $(13.65 \%)$, aliphatic hydrocarbons $(7.90 \%)$, aromatic compounds $(4.10 \%)$, monoterpene hydrocarbons $(2.33 \%)$, triterpene $(1.43 \%)$, sesquiterpene oxygen-containing derivatives $(1.23 \%)$, diterpene $(0.52 \%)$ and aliphatic oxygen-containing derivatives $(0.37 \%)$. In the extract obtained from humid leaves dominated monoterpene oxygencontaining derivatives $(72.19 \%)$, sesquiterpenehydrocarbons $(15.41 \%)$, aromatic compounds $(4.32 \%)$, aliphatic hydrocarbons $(3.64 \%)$, monoterpene hydrocarbons $(2.45 \%)$, triterpene $(0.66 \%)$, sesquiterpene oxygen-containing derivatives $(0.70 \%)$, aliphatic oxygen-containing derivatives $(0.39 \%)$ and diterpene $(0.24 \%)$.

Dressings with an oil extract of humid leaf had most intensive smell of laurel leaf. The same is true when this sample was also perceived with the most intensive taste of laurel leaf. The sour and salt taste was equally appreciated for all three samples.

The oil extract obtained from humid leaves was preferred and between the oil extract obtained from dry leaves and the control sample the evaluators didn't not express a preference. A higher total score was obtained by salad dressing with an oil extract obtained from humid leaves.

Conclusion. Oil extract obtained from humid leaves was preferred and between the oil extract obtained from dry leaves and the control sample the evaluators didn't express a preference. A higher total score was obtained by salad dressing with an oil extract obtained from humid leaves. 


\section{Introduction}

Laurel (Laurus nobilis L.) is a perennial plant of the family Lauraceae. It is believed that it originates from Asia Minor from where it was transferred to the Balkan Peninsula and the Mediterranean. Nowadays the laurel is distributed area of Europe, North Africa and Asia. In Bulgaria, this tree or shrub is cultivated in gardens of the homes and in the most southern regions - the cities Petrich and Sandanski as well as in the northeastern parts of the country $[3,4,5,12]$.

Fresh or dried laurel leaves are used widely in the food industry as flavors and preservatives for marinating meat and vegetables dishes, canned foods, fish dishes, sauces, soups, food emulsions etc. $[4,9,16]$. Antimicrobial and antioxidant activities are other factors for aromatic products from laurel leaves to be used in the food products as a food preservative $[4,5,12]$.

Emulsions take place in the structures of many natural and processed foods and significant part of these foods are mayonnaise-type products. An oil-in-water emulsion can be used in the production of sweet sauces and salad dressings. Today, their formulation include not only glyceride oils rich in polyunsaturated fatty acids $[6,7,8]$, but also essential oil extracts containing different biologically active substances $[2,4]$.

No studies have been reported on the obtaining of essential oil extracts from laurel (Laurus nobilis $L$.) leaves and their practice application in food products.

The objective of this study was to characterize essential oil extracts from laurel (Laurus nobilis L.) leaves and to develop sensory profiles of salad dressings with these extracts.

\section{Materials and methods}

\section{Plant material}

Laurel leaves (Laurus nobilis L.) originating from the Athon peninsula, northern Greece were used and they were picked in October 2016.

\section{Moisture content determination}

The row materials moisture content was determined by drying up to constant weight, at $105^{\circ} \mathrm{C}[11]$.

The wetness of the leaves - fresh (36.69\%) and air-dry after shade drying (4.76\%) was determined by drying to constant mass at $105{ }^{\circ} \mathrm{C}$ [11]. The essential oil content of the leaves was $2.34 \%[10]$.

\section{Aromatic compounds extraction}

Extraction was carried out as a batch static process by maceration in the solvent at a ratio of raw material to solvent $=1: 10$ under the following conditions: solvent - sunflower oil; temperature $-60{ }^{\circ} \mathrm{C}$; size of material particles $-1.0 \times 1.5 \mathrm{~cm}$; duration of extraction 5,7 and $9 \mathrm{~h}$. As a criterion for effectiveness of the process the quantity of aromatic compounds was determined. 
The oils were prepared by hydrodistilled for $3 \mathrm{~h}$ in laboratory glass apparatus of British Pharmacopoeia, modified by Balinova and Diakov [1]. The oils were dried over anhydrous sulfate and were stored in tightly closed dark vials at $4{ }^{\circ} \mathrm{C}$ until analysis.

The separation of the row material from the obtained extraction aromatic products was made by filtration trough filter paper.

\section{Aromatic compounds determination}

The content of aromatic products in oil extracts was determined by water distillation in laboratory glass apparatus of British Pharmacopoeia, modified by Balinova and Diakov [15]. The distillation was continued for $3 \mathrm{~h}$ and was ended when two consecutive measurements in 30 minutes didn't show an increase in the amount of essential oil [11].

The amount of essential oil non-extracted from the raw material was determined by water distillation in the apparatus described above under the same technological parameters.

After distillation, the leaves could be used to fertilize or to produce other biologically active substances.

\section{GC/MS analysis of oil extracts}

The physico-chemical properties of experimental extracts were measured [11]. GC analysis was performed using gas chromatograph Agilent $7890 \mathrm{~A}$; column HP-5 ms (30m $\times$ $250 \mu \mathrm{m} \times 0.25 \mu \mathrm{m}$ ); temperature: $35{ }^{\circ} \mathrm{C} / 3 \mathrm{~min}, 5{ }^{\circ} \mathrm{C} / \mathrm{min}$ to $250{ }^{\circ} \mathrm{C}$ for $3 \mathrm{~min}$, total $49 \mathrm{~min}$; carrier gas helium $1 \mathrm{ml} / \mathrm{min}$ constant speed; split ratio $30: 1$. GC/MS analysis was carried out on a mass spectrometer Agilent 5975C, carrier gas helium, column and temperature the same as the GC analysis.

The identification of chemical compounds was made by comparison to their relative retention time and library data. The identified components were arranged in order to the retention time and quantity in percentage.

\section{Technology of Dressing's production}

The salad dressings, which belong to oil-in-water emulsions, were produced by established technology [8] with the addition of essential oil extracts from dried and humid laurel leaves.

The following ingredients for salad dressings were used: dry egg melange $-4 \%$, refined sunflower oil $-5 \%$ and oil extracts from laurel leaves $-5 \%$.

Starch $-4 \%$ and gum (mix of gum guar and gum xanthan) $-0.1 \%$ were used as structure stabilizers of products.

The starch, gum and water were heated to $80{ }^{\circ} \mathrm{C}$ and then the mixture was cooled to 20 ${ }^{\circ} \mathrm{C}$. The sunflower oil and extract were added to the mixture and homogenized together with citric acid $-0.1 \%$ and salt $-1 \%$.

A control sample without essential oil extracts was developed.

\section{Sensory analysis of salad dressings}

Sensory evaluation was performed by a trained sensory panel consisting of 10 trained assessors. The samples were at a temperature of $10{ }^{\circ} \mathrm{C} \pm 1{ }^{\circ} \mathrm{C}$ and equal quantities $(5 \mathrm{~g})$ placed on white plastic glass, labelled with a three-digit code and served to the panel in random order.

Specific attributes and sensory descriptors of salad dressings were defined (Table 1). 


\section{Main parameters used for sensory evaluation of salad dressings}

\begin{tabular}{|c|l|l|}
\hline № & \multicolumn{1}{|c|}{$\begin{array}{c}\text { Specific sensory } \\
\text { attributes }\end{array}$} & \multicolumn{1}{c|}{ Sensory descriptors } \\
\hline 1 & Appearance & $\begin{array}{l}\text { Color (intensity of yellow color (white to yellow), brightness, } \\
\text { emulsion stability }\end{array}$ \\
\hline 2 & Texture & Consistency (fluid to firm), adhesion, oiliness, homogeneity \\
\hline 3 & Smell & Laurel leaf, rancidity \\
\hline 4 & Taste & Salty, laurel leaf, rancidity, sour \\
\hline 5 & Aftertaste & Bitter, laurel leaf \\
\hline 6 & Overall acceptability & Bad to very good \\
\hline
\end{tabular}

Each attribute was quantified by intensity of perception (amplitude) with a numeric value from 0 to 9 , corresponding to "no stimulus" to "extremely strong stimulation". Each attribute had individually scale and after the statistical evaluation, the results were graphically presented. Sensory profiles of salad dressings were demonstrated.

All measurements were conducted in triplicate and the mean values were presented in the tables and graphs.

\section{Results and discussion}

The amount of flavoring substances (relative to the extracts) was as follows: at $5 \mathrm{~h}-$ $0.02 \%$, at $7 \mathrm{~h}-0.03 \%$, at $9 \mathrm{~h}-0.03 \%$. With increasing the duration of extraction from 5 to 7 hours, increase the content of flavoring substances by $50 \%$ and then remains unchanged regardless of time.

The air-dry leaves were moistened with water to reach humidity of the fresh leaves and after being kept in a closed vessel for 12 hours (for a more complete diffusion of water in the dry leaves) were extracted. The quantity of flavoring substances in the oil extracts was $0.03 \%$ and it did not differentiate each other. In the processed raw material, the content of flavoring substances ranged from 2.2 to $2.25 \%$.

Sensory attributes and chemical content in the oil extracts were measured after $7 \mathrm{~h}$ extraction and then the same extracts were added in salad dressing's formulation.

The oil extracts were different regarding to their aroma and the sample with humid leaves had more pronounced smell (Table 2).

Attributes of essential oil extracts

Table 2

\begin{tabular}{|l|c|c|}
\hline Attributes & From dry leaves & From humid leaves \\
\hline Appearance & \multicolumn{2}{|c|}{ Oily fluid } \\
\hline Color & \multicolumn{2}{|c|}{ Yellow } \\
\hline Smell & Specific & Strong, Specific \\
\hline
\end{tabular}

Chemical composition of the extracts was determined and is listed in Table 3. 
Table 3

Percentage composition of the extracts, \%

\begin{tabular}{|c|c|c|c|c|}
\hline № & Components & RI & From dry leaves & From humid leaves \\
\hline 1 & $\alpha$-pinene & 939 & 0.35 & 0.37 \\
\hline 2 & Camphenaн & 954 & 0.31 & 0.31 \\
\hline 3 & Sabinene & 971 & 0.10 & 0.11 \\
\hline 4 & $\beta$-pinene & 979 & 0.28 & 0.30 \\
\hline 5 & $\beta$-myrcene & 991 & 0.11 & 0.12 \\
\hline 6 & $\delta$-2-carene & 1001 & 0.05 & 0.06 \\
\hline 7 & $\delta$-3-carene & 1007 & 0.21 & 0.21 \\
\hline 8 & p-cymene & 1025 & 3.12 & 3.28 \\
\hline 9 & 1,8-cineole & 1032 & 43.65 & 45.94 \\
\hline 10 & $\beta$-ocimene & 1040 & 0.15 & 0.16 \\
\hline 11 & $\gamma$-terpinene & 1055 & 0.52 & 0.54 \\
\hline 12 & Terpinene & 1087 & 0.33 & 0.35 \\
\hline 13 & $\beta$-linalool & 1096 & 0.67 & 0.70 \\
\hline 14 & n-nonanal & 1128 & 0.18 & 0.19 \\
\hline 15 & Verbenol & 1131 & 0.20 & 0.21 \\
\hline 16 & L-trans-pinocarveole & 1137 & 0.23 & 0.25 \\
\hline 17 & cis- $\beta$-terpineol & 1143 & 0.55 & 0.58 \\
\hline 18 & Pinocarvone & 1152 & 0.26 & 0.28 \\
\hline 19 & terpinen-4-ol & 1179 & 2.88 & 3.03 \\
\hline 20 & $\alpha$-terpineol & 1189 & 2.31 & 2.44 \\
\hline 21 & Nerol & 1229 & 0.10 & 0.10 \\
\hline 22 & 2-decanal & 1230 & 0.18 & 0.19 \\
\hline 23 & Bornyl acetate & 1269 & 0.21 & 0.22 \\
\hline 24 & $\alpha$-terpenyl acetate & 1333 & 15.10 & 15.89 \\
\hline 25 & eugenol & 1363 & 0.15 & 0.16 \\
\hline 26 & $\beta$-elemene & 1368 & 0.23 & 0.24 \\
\hline 27 & methyleugenol & 1371 & 0.52 & 0.55 \\
\hline 28 & ilangene & 1387 & 0.13 & 0.14 \\
\hline 29 & calarene & 1426 & 8.48 & 8.92 \\
\hline 30 & $\beta$-caryophyllene & 1426 & 0.22 & 0.23 \\
\hline 31 & $\alpha$-humulene & 1453 & 0.09 & 0.09 \\
\hline 32 & Germacrene D & 1484 & 0.43 & 0.45 \\
\hline 33 & $\beta$-bisabolene & 1502 & 3.89 & 5.09 \\
\hline 34 & Caryophyllene oxide & 1574 & 0.39 & 0.18 \\
\hline 35 & (-)-spathulenol & 1619 & 0.58 & 0.27 \\
\hline 36 & n-heptadecane & 1700 & 0.33 & 0.15 \\
\hline 37 & n-heneicosane & 2100 & 1.05 & 0.49 \\
\hline 38 & Phytol & 2105 & 0.50 & 0.23 \\
\hline 39 & n-docosane & 2200 & 1.00 & 0.46 \\
\hline 40 & n-tricosane & 2300 & 0.66 & 0.31 \\
\hline 41 & n-tetracosane & 2400 & 0.64 & 0.29 \\
\hline 42 & n-pentacosane & 2500 & 0.94 & 0.43 \\
\hline 43 & n-hexacosane & 2600 & 1.20 & 0.55 \\
\hline 44 & n-heptacosane & 2700 & 1.37 & 0.63 \\
\hline 45 & octacosane & 2800 & 0.48 & 0.22 \\
\hline 46 & squalene & 2817 & 1.39 & 0.64 \\
\hline
\end{tabular}


In extract from dry leaves as seen 46 components representing $97.06 \%$ of the total content were identified. Twelve of them were in concentrations over $1 \%$ and the rest 34 constituents were in concentrations under $1 \%$. The main components (above $3 \%$ ) were: 1,8 cineole $(43.65 \%), \alpha$-terpinyl acetate $(15.10 \%)$, calarene $(8.48 \%), \beta$-bisabolene $(3.89 \%)$ and p-cymene $(3.12 \%)$.

In extract, from humid leaves as seen 46 components representing $96.91 \%$ of the total content, were identified. Seven of them were in concentrations over $1 \%$ and the rest 39 constituents were in concentrations under $1 \%$. The main components (above 3\%) were: 1,8 cineole $(45.94 \%), \alpha$-terpenyl acetate $(15.89 \%)$, calarene $(8.92 \%), \beta$-bisabolene $(5.09 \%), p$ cymene (3.28\%) and terpinen-4-ol (3.03\%).

The two extracts had difference by content of aromatic components from those obtained with ethanol $(30,50,70$ and $95 \%)$ [10], which might be explained by the selectivity of the extractants. There were differences in the composition of the essential oils [10], and this was probably due to the method of production.

The distribution of the major aromatic compounds in the two oil extracts is shown in Figure 1.

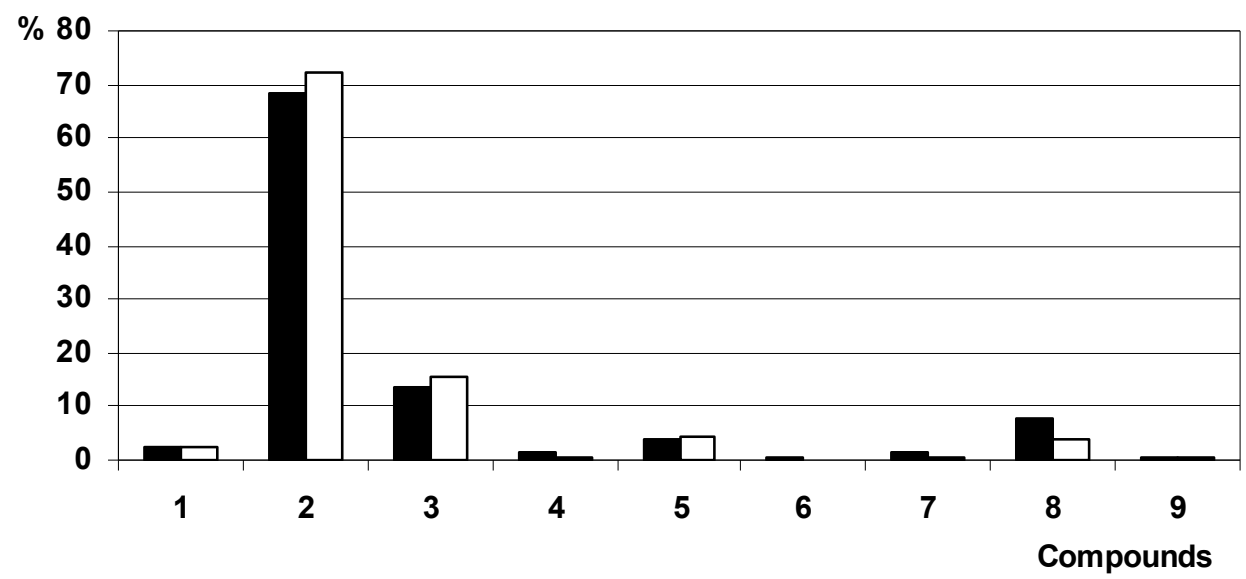

- Dry leaves

$\square$ Humid leaves

Figure 1. Group of components in essential oils from extracts, \%

1 - monoterpene hydrocarbons; 2 - oxygenated monoterpenes; 3 -sesquiterpene hydrocarbons; 4 - oxygenated sesquiterpenes; 5 - phenyl propanoids; 6 -diterpenes; 7 - triterpenes;

8 - alyphatic hydrocarbons; 9 - oxygenated alyphatics.

The data showed that:

- In the extract obtained from dry leaves dominated monoterpene oxygen-containing derivatives $(68.47 \%)$, followed by sesquiterpene hydrocarbons (13.65\%), aliphatic hydrocarbons $(7.90 \%)$, aromatic compounds $(4.10 \%)$, monoterpene hydrocarbons (2.33\%), triterpene $(1.43 \%)$, sesquiterpene oxygen-containing derivatives $(1.23 \%)$, diterpene $(0.52 \%)$ and aliphatic oxygen-containing derivatives $(0.37 \%)$.

- In the extract obtained from humid leaves dominated monoterpene oxygen-containing derivatives $(72.19 \%)$, followed by sesquiterpenehydrocarbons $(15.41 \%)$, aromatic compounds (4.32\%), aliphatic hydrocarbons (3.64\%), monoterpene hydrocarbons $(2.45 \%)$, triterpene $(0.66 \%)$, sesquiterpene oxygen-containing derivatives $(0.70 \%)$, aliphatic oxygen-containing derivatives $(0.39 \%)$ and diterpene $(0.24 \%)$. 
Oil extracts had difference from essential oil and ethanol extracts [10] by content of the essential monoterpenic oxygen-containing derivatives that were odor-determining components, although they were derived from the same raw material (Figure 2). This can be attributed the way of production for the other two products - oil distillation and extraction and the use of different technological parameters - extractor, temperature, and duration.

Other authors [4] had found similar dependencies on the differences in the composition of different flavoring products obtained from the same raw material.

The results of sensory evaluation of the salad dressings are shown in Table 4. The color perception of the samples was perceived as equal according to the data from the analysis of appearance. According to the evaluators, dressings had a bright, almost white color, due to the low content of the oil in the formulation. The addition of extracts from laurel leaves had no effect on the color characteristics of the food products. Other authors also confirm the bright color of low-fat food emulsions, which, in their opinion, is also due to the presence of thickening agents (starch and gums) [14].

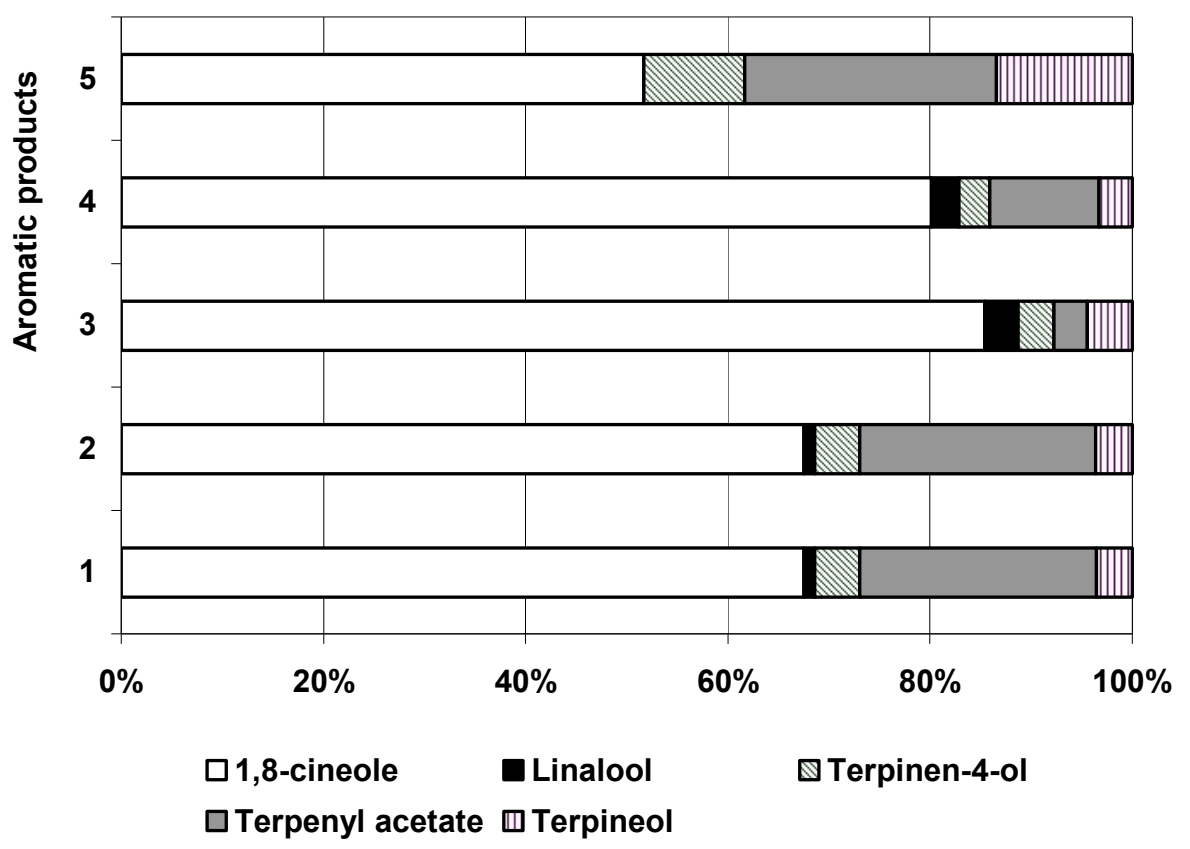

Figure 2. Distribution of monoterpene oxygen-containing derivatives

1 - oil extracts fron dry leaves; 2 - oil extract from humid leves; 3 - extract with $30 \%$ ethanol; 4 - extract with $50 \%$ ethanol; 5- essential oil 
Sensory evaluation of salad dressings with extracts from laurel leaves

\begin{tabular}{|l|c|c|c|}
\hline \multicolumn{1}{|c|}{ Attributes } & $\begin{array}{c}\text { Control } \\
\text { sample }\end{array}$ & $\begin{array}{c}\text { Salad dressings } \\
\text { with extract from } \\
\text { dry leaves }\end{array}$ & $\begin{array}{c}\text { Salad dressings with } \\
\text { extract from humid } \\
\text { leaves }\end{array}$ \\
\hline Yellow color & $3.0 \pm 1.4 \mathrm{a}$ & $3.7 \pm 1.4 \mathrm{a}$ & $3.0 \pm 0.9 \mathrm{a}$ \\
\hline Brightness & $3.0 \pm 0.9 \mathrm{a}$ & $2.7 \pm 0.8 \mathrm{a}$ & $2.5 \pm 1.0 \mathrm{a}$ \\
\hline Stability & $8.0 \pm 1.3 \mathrm{a}$ & $7.5 \pm 1,8 \mathrm{a}$ & $8.8 \pm 0.4 \mathrm{~b}$ \\
\hline Consistency (fluid to firm) & $4.0 \pm 1.8 \mathrm{a}$ & $3.8 \pm 1.5 \mathrm{a}$ & $4.2 \pm 1.9 \mathrm{a}$ \\
\hline Adhesion (adhesiviness) & $1.8 \pm 1.0 \mathrm{a}$ & $1.7 \pm 0.8 \mathrm{a}$ & $1.7 \pm 0.8 \mathrm{a}$ \\
\hline Oiliness & $3.2 \pm 1.2 \mathrm{a}$ & $3.5 \pm 1.4 \mathrm{a}$ & $3.5 \pm 1.4 \mathrm{a}$ \\
\hline Homogeneity & $7.3 \pm 1.0 \mathrm{a}$ & $7.7 \pm 0.5 \mathrm{a}$ & $7.8 \pm 0.8 \mathrm{a}$ \\
\hline Smell - laurel leaf & $1,3 \pm 0,8 \mathrm{a}$ & $4.8 \pm 1.0 \mathrm{~b}$ & $7.5 \pm 1.2 \mathrm{c}$ \\
\hline Rancidity smell & $1.5 \pm 0.5 \mathrm{a}$ & $1.5 \pm 0.5 \mathrm{a}$ & $1.5 \pm 0.5 \mathrm{a}$ \\
\hline Salty taste & $4.0 \pm 1.4 \mathrm{a}$ & $4.2 \pm 1.0 \mathrm{a}$ & $4.5 \pm 1.0 \mathrm{a}$ \\
\hline Taste - laurel leaf & $1.2 \pm 0.4 \mathrm{a}$ & $5.8 \pm 0.8 \mathrm{~b}$ & $7.7 \pm 1.0 \mathrm{c}$ \\
\hline Rancidity taste & $1.3 \pm 0.5 \mathrm{a}$ & $1.3 \pm 0.5 \mathrm{a}$ & $1.3 \pm 0.5 \mathrm{a}$ \\
\hline Sour taste & $2.2 \pm 1.0 \mathrm{a}$ & $2.8 \pm 1.2 \mathrm{a}$ & $2.7 \pm 1.2 \mathrm{a}$ \\
\hline Bitter aftertaste & $1.2 \pm 0.4 \mathrm{a}$ & $1.8 \pm 0.8 \mathrm{a}$ & $1.8 \pm 0.8 \mathrm{a}$ \\
\hline Bitter aftertaste & $1.2 \pm 0.4 \mathrm{a}$ & $1.8 \pm 0.8 \mathrm{a}$ & $1.8 \pm 0.8 \mathrm{a}$ \\
\hline Aftertaste - laurel leaf & $1.8 \pm 1.0 \mathrm{a}$ & $6.0 \pm 1.1 \mathrm{~b}$ & $7.2 \pm 0.8 \mathrm{c}$ \\
\hline Overall acceptability & $5.5 \pm 1.4 \mathrm{a}$ & $5.2 \pm 1.3 \mathrm{a}$ & $7.3 \pm 1.2 \mathrm{~b}$ \\
\hline
\end{tabular}

Means \pm SD values followed by the same letter in each line are not significant different at $\mathrm{p} \leq 0.05$ by ANOVA

In terms of stability, all products were accepted at equal sensory stability. There was no separation of oil on the surface of the products. Regarding to the viscosity, the evaluators defined dressings as products with a flowing consistency.

It was observed that dressings with an oil extract of humid leaf had most intensive smell of laurel leaf. This is explained by the higher content of monoterpenic oxygencontaining derivatives that are responsible for taste and aroma. The same is true when this sample was also perceived with the most intensive taste of laurel leaf. It was also found out that the sour and salt taste was equally appreciated for all three samples because of the same amounts of salt and citric acid used in their composition.

The evaluators didn't take into account the rancid flavor of the products, which is an indicator of the vegetable oil quality.

After consumption of the emulsion products, the after taste of the laurel leaf, determined with the highest intensity of perception, was more pronounced in products with oil extract obtained from humid leaves. Bitter aftertaste was almost unrecognizable in all three samples.

The results for the overall acceptability of the three products showed that the oil extract obtained from humid leaves was preferred and between the oil extract obtained from dry leaves and the control sample the evaluators didn't not express a preference. A higher total score was obtained by salad dressing with an oil extract obtained from humid leaves.

Experimental data from Figure 3 and Figure 4 shows the perceived attributes of the investigated samples graphically presented. 

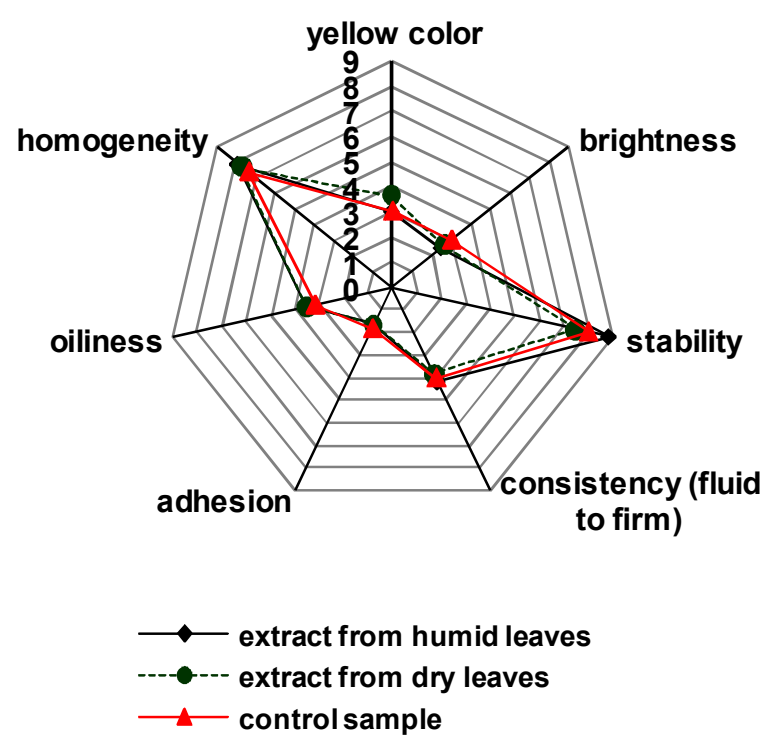

Figure 3. Appearance and texture sensory profiles of salad dressings with oil extracts from laurel leaves
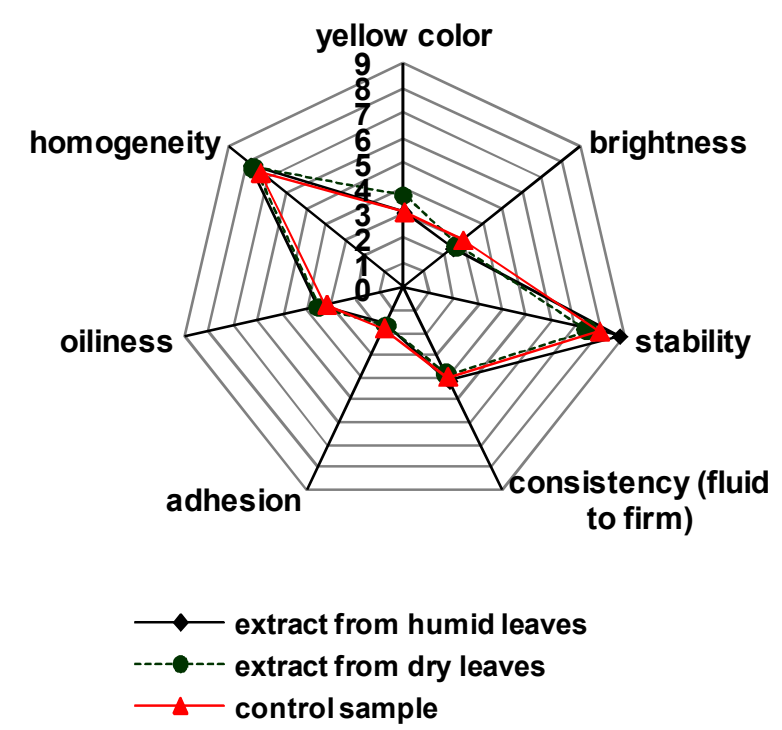

Figure 4. Smell and taste sensory profiles of salad dressings with oil extracts from laurel leaves 


\section{Conclusion}

Extracts from laurel leaves are appropriate ingredients of salad dressings and they improve sensory profiles of food products. Oil extract obtained from humid leaves was preferred and between the oil extract obtained from dry leaves and the control sample the evaluators didn't express a preference. A higher total score was obtained by salad dressing with an oil extract obtained from humid leaves.

\section{References}

1. António Marques, Bárbara Teixeira, Maria Leonor Nunes (2016), Chapter 26: Bay Laurel (Laurus nobilis) Oils, Essential Oils in Food Preservation, Flavor and Safety, Elsevier Inc, pp. 239-246

2. Boeva A., Noninska L., Tzanova M. (1990), Spices as food and medicine, Sofia, Medicine and Gymnastic Press, pp. 54-56.

3. Voitkevich S. (1999), Essential oils for perfumery and aromatherapy, Food Science Press Moscow.

4. Georgiev E., Stoyanova A. (2006), A guide to the specialist in the aromatic industry, BNAEMPK, Plovdiv.

5. Denkova Z., Denkov V. (1999), Aromatherapy guide, Emas Press, Sofia, pp. 256-257.

6. Nikovska K. (2008), Possibilities for using walnut oil in food emulsion technology. $\mathrm{PhD}$ Thesis, UFT, Plovdiv.

7. Nikovska K. (2008), Emulsion food products for catering and culinary production, Scientific works for Union of Scientist, Plovdiv, 10, pp. 7-11.

8. Nikovska K., Stamov S. (2009), Technology and content of food emulsions with olive oil, Scientific works UFT, 61, pp. 29-34.

9. Riman D. (2004), Aromatherapy bible, Hermes Press, Plovdiv.

10. Stefanova G., Tasheva S., Stefanov L., Damyanova S., Stoyanova A. (2017), Derivation and analysis of laurel leaves extracts (Laurus nobilis L.), Industrial technologies, 4.

11. Stoyanova A., Georgiev E., Atanasova T. (2007), Handbook for laboratory exercises on essential oils, Akad. Press UFT, Plovdiv.

12. Topalov P. (1962), Row material science for essential and vegetables oils, Danov Press, Plovdiv, pp. 187-190.

13. Tolga Akcan, Mario Estévez, Meltem Serdaroğlu (2017), Antioxidant protection of cooked meatballs during frozen storage by whey protein edible films with phytochemicals from Laurus nobilis L. and Salvia officinalis, LWT - Food Science and Technology, 77, pp. 323-331

14. Karas R., Skvarca M., Zlender B. (2002), Sensory quality of standard and light mayonnaise during storage, Food technology Biotechnology, 40, pp. 119-127.

15. Balinova A., Dyakov G. (1974), Improved micro-distillation apparatus for blossom of roses, Plant Breeding Science, 11, pp. 79-85.

16. Stereva R., Georgiev E., Dimitrov D. (1987), Possibilities for vinegar flavoring. Jubilee Scientific Session "80 Years Scientific Research on Essential Oils and Medicinal Plants", Kazanlak, 21-22 October 1987.

17. Mohammad Chmit, Hussein Kanaan, Jean Habib, Mustafa Abbass, Ali Chokr (2014), Antibacterial and antibiofilm activities of polysaccharides, essential oil, and fatty oil extracted from Laurus nobilis growing in Lebanon, Asian Pacific Journal of Tropical Medicine, 7(1), pp. 546-552. 